\title{
ARTICLE
}

Received 16 Apr 2015 | Accepted 10 Nov 2015 | Published 18 Dec 2015

DOI: $10.1038 /$ ncomms10159 OPEN

\section{ChIP-seq reveals broad roles of SARD1 and CBP60g in regulating plant immunity}

Tongjun Sun ${ }^{1}$, Yaxi Zhang ${ }^{2}$, Yan $\mathrm{Li}^{2}$, Qian Zhang ${ }^{1}$, Yuli Ding ${ }^{1} \&$ Yuelin Zhang ${ }^{1}$

Recognition of pathogens by host plants leads to rapid transcriptional reprogramming and activation of defence responses. The expression of many defence regulators is induced in this process, but the mechanisms of how they are controlled transcriptionally are largely unknown. Here we use chromatin immunoprecipitation sequencing to show that the transcription factors SARD1 and CBP60g bind to the promoter regions of a large number of genes encoding key regulators of plant immunity. Among them are positive regulators of systemic immunity and signalling components for effector-triggered immunity and PAMP-triggered immunity, which is consistent with the critical roles of SARD1 and CBP60g in these processes. In addition, SARD1 and CBP60g target a number of genes encoding negative regulators of plant immunity, suggesting that they are also involved in negative feedback regulation of defence responses. Based on these findings we propose that SARD1 and CBP60g function as master regulators of plant immune responses.

\footnotetext{
${ }^{1}$ Department of Botany, University of British Columbia, Vancouver, British Columbia, Canada V6T 1Z4. ${ }^{2}$ National Institute of Biological Sciences, Beijing, 102206, China. Correspondence and requests for materials should be addressed to Y.L.Z. (email: yuelin.zhang@ubc.ca).
} 
P lants use a multilayered defence system to combat microbial pathogens. At the front line, pattern recognition receptors on the plasma membrane recognize conserved features of microbes, collectively known as microbe-associated molecular patterns or pathogen-associated molecular patterns (PAMPs), to activate PAMP-triggered immunity (PTI $)^{1}$. Most PAMP receptors belong to the receptor-like kinase and the receptorlike protein families. A second line of plant defence called effector-triggered immunity (ETI) relies on resistance (R) proteins that detect effector proteins secreted by pathogens to inhibit PTI (ref. 2). The majority of plant R proteins belong to the intracellular nucleotide-binding site $(\mathrm{NB})$ leucine-rich repeats (LRR) protein family. Recognition of pathogens and activation of local defence responses further induce a secondary immune response in the distal part of plants termed systemic acquired resistance $(\mathrm{SAR})^{3}$.

Salicylic acid (SA) is a signal molecule that plays key roles in local defence and SAR (ref. 4). SALICYLIC ACID INDUCTIONDEFICIENT 2 (SID2) and ENHANCED DISEASE SUSCEPTIBILITY 5 (EDS5) are required for pathogen-induced SA accumulation ${ }^{5,6}$. Mutations in SID2 or EDS5 block the accumulation of SA, resulting in enhanced susceptibility to pathogens and loss of SAR (refs 5-7). SID2 encodes Isochorismate Synthase 1 (ICS1), which is a key enzyme in pathogen-induced SA synthesis ${ }^{6}$. EDS5 encodes a transporter involved in exporting SA from chloroplast to cytoplasm ${ }^{8,9}$. Activation of defence gene expression and pathogen resistance by SA depends on the downstream component NON-EXPRESSOR OF PATHOGENESIS RELATED GENES1 (NPR1) ${ }^{10}$. Recent studies showed that NPR1 and its paralogs, NPR3 and NPR4, bind to SA and may function as SA receptors ${ }^{11,12}$.

Several genes encoding enzymes implicated in the synthesis of secondary metabolites have also been identified to be essential for SAR. Among them, FLAVIN-DEPENDENT MONOOXYGENASE1 (FMO1) encodes a putative monooxygenase ${ }^{13-15}$, AGD2LIKE DEFENSE RESPONSE PROTEIN1 (ALD1) encodes an aminotransferase ${ }^{16}$, and avrPphB SUSCEPTIBLE3 (PBS3) encodes a member of the firefly luciferase superfamily ${ }^{17-19}$. In fmo1, ald 1 and pbs 3 mutants, SAR is severely compromised $^{15,20,21}$. ALD1 is involved in the synthesis of pipecolic acid, which contributes to the induction of SAR (ref. 22), while the chemicals synthesized by FMO1 and PBS3 remain to be determined.

Two pathogen-induced transcription factors, SAR DEFICIENT1 (SARD1) and CAM-BINDING PROTEIN 60-LIKE G (CBP60g), regulate the expression of ICS1 and are required for pathogen induction of SA synthesis ${ }^{23-25}$. Following pathogen infection, SARD1 and CBP60g are recruited to the promoter of ICS1 (ref. 24). In the sard 1 cbp60g double mutant, induction of ICS1 expression and SA synthesis is blocked ${ }^{24,25}$. SARD1 and CBP60g belong to the same protein family but are regulated differently, suggesting that they function in two parallel pathways to activate ICS1 expression ${ }^{23,24}$. CBP60g, but not SARD1, can bind calmodulin. On the other hand, overexpression of $S A R D 1$, but not $C B P 60 \mathrm{~g}$, leads to constitutive activation of defence responses.

Arabidopsis SNC2 encodes an receptor-like protein that is required for resistance against pathogenic bacteria Pseudomonas syringae pv tomato (P.s.t.) DC3000 and non-pathogenic bacteria $P$. syringae pv tomato DC3000 hrcC (refs 26,27). A gain-of-function mutation in snc2-1D leads to constitutive activation of both SA-dependent and SA-independent defence pathways ${ }^{26}$. The snc2-1D mutant has small stature, accumulates high levels of salicylic acid, constitutively expresses PATHOGENESIS-RELATED (PR) genes, and exhibits enhanced pathogen resistance. From a suppressor screen of snc2-1D npr1-1, WRKY DNA-BINDING PROTEIN 70 (WRKY70) was identified as an essential regulator of the SA-independent pathway downstream of $s n c 2-1 D$ (ref. 26).

Here we report that SARD1 and CBP60g regulate not only the expression of ICS1 and SA synthesis, but also the expression of WRKY70 and the SA-independent defence pathway in snc2-1D. Chromatin immunoprecipitation (ChIP) analysis revealed that a large number of plant defence regulators including WRKY70 are direct binding targets of SARD1 and CBP60g suggesting that SARD1 and CBP60g function as master regulators of plant defence responses.

\section{Results}

SARD1 and CBP60g are required for autoimmunity in snc2-1D. To determine whether the increased SA synthesis in snc2-1D mutant plants is dependent on SARD1 and CBP60g, we crossed sard1-1 and $\operatorname{cbp} 60 \mathrm{~g}-1$ into $s n c 2-1 D$ to obtain the sard1-1 snc2-1D and $\operatorname{cbp} 60 \mathrm{~g}-1$ snc2-1D double mutants and the sard1-1 cbp60g-1 snc2-1D triple mutant. Quantitative reverse transcription PCR (RT-PCR) analysis showed that the expression of ICS1 in snc2-1D is much higher than in wild type, but the increased expression of ICS1 is blocked in the sard1-1 cbp60g-1 snc2-1D triple mutant (Fig. 1a). Consistent with the expression levels of ICS1, increased accumulation of SA in $s n c 2-1 D$ is also suppressed in the triple mutant (Fig. 1b).

The sard1-1 snc2-1D and cbp60g-1 snc2-1D double mutants have similar morphology as snc2-1D and are only slightly bigger than $s n c 2-1 D$ (Fig. 1c). Surprisingly, the mutant morphology of snc2-1D is almost completely suppressed in the sard1-1 cbp60g-1 snc2-1D triple mutant (Fig. 1d). Quantitative RT-PCR analysis showed that the expression levels of defence marker genes PR1 and PR2 are slightly lower in the double mutants but are markedly reduced in the triple mutant compared with snc2-1D (Fig. 1d,e). In addition, the enhanced resistance to Hyaloperonospora arabidopsidis Noco 2 in $s n c 2-1 D$ is partially reduced in the double mutants and almost completely lost in the triple mutant (Fig. 1f). As blocking SA accumulation by eds5-3 has very little effect on the morphology, $P R 2$ expression and resistance to $H$. arabidopsidis Noco2 in snc2-1D (ref. 26), these data suggest that SARD1 and CBP60g also regulate SA-independent pathways in $s n c 2-1 D$.

SARD1 and CBP60g regulate the expression of WRKY70. In sard1 cpb60g mutant plants expressing the SARD1-HA fusion protein under its native promoter, pathogen-induced ICS1 expression was restored to similar level as in the $c b p 60 g$ single mutant, suggesting that SARD1-HA functions similarly as wildtype SARD1 protein (Supplementary Fig. 1). To identify genes targeted by SARD1, ChIP was carried out on transgenic plants expressing a SARD1-HA fusion protein under its own promoter using an anti-HA antibody. The immunoprecipitated DNA was sequenced by Illumina sequencing. Analysis of the ChIPsequencing (ChIP-seq) data showed a $\times 20$ genome coverage.

Sequence coverage at each position on the genome was plotted to identify peaks in the Arabidopsis genome. Analysis of peaks in the genic region showed that most sequence peaks are located in the $1.5 \mathrm{~kb}$ region upstream of the translation start site, which includes the 5'-UTRs and promoter regions. After removing genes that showed similar sequence peaks in the negative control, peaks with heights of 90 or greater were found in the introns of 84 genes, the 3'-UTRs of 60 genes and the $1.5 \mathrm{~kb}$ region upstream of the translation start sites of 1,902 genes. We focused our analysis on the group containing peaks with heights of 90 or greater in the $1.5 \mathrm{~kb}$ region upstream of the translation start sites (Supplementary Data 1), because it contains many genes encoding known regulators of plant defence that are strongly 
a

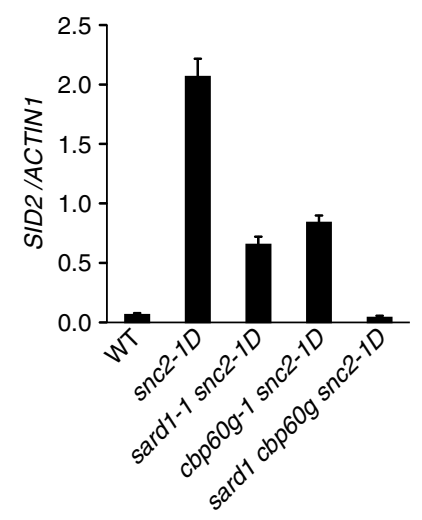

b

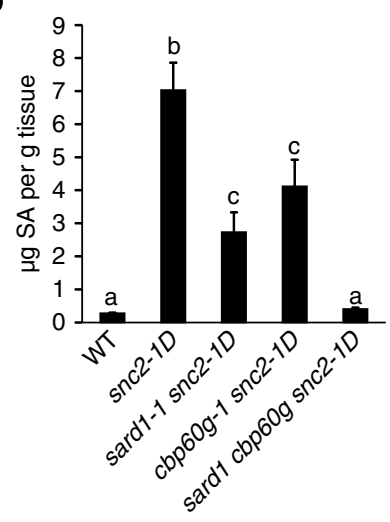

C

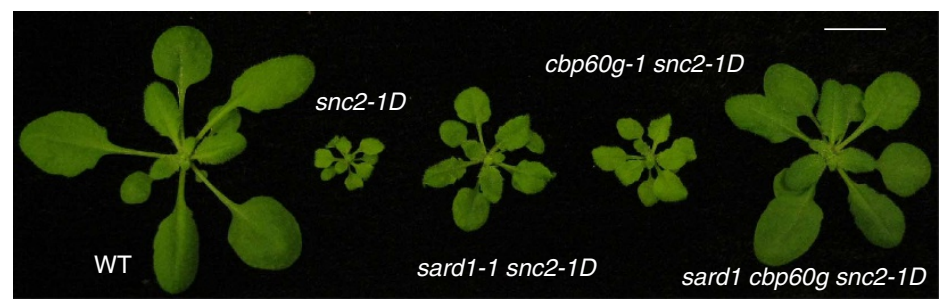

d

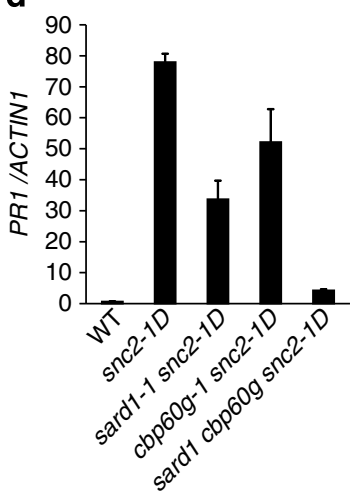

e

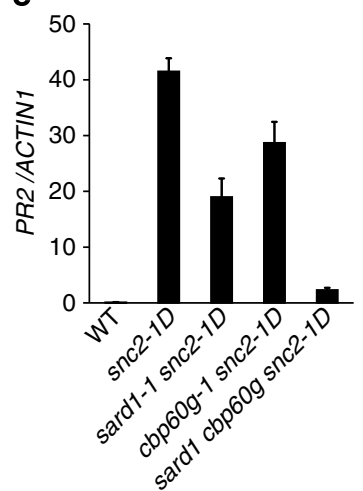

f

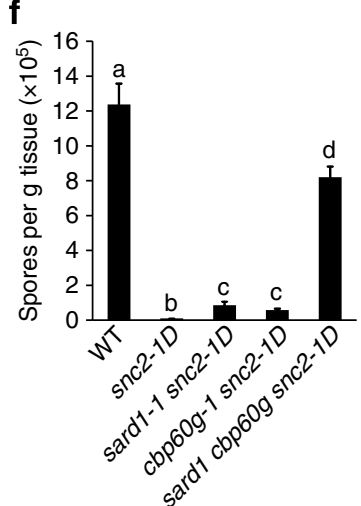

Figure 1 | Mutations in SARD1 and CBP60g largely suppress snc2-1D-mediated autoimmunity. (a) SID2 expression in wild-type Col-0, snc2-1D, sard1-1 snc2-1D, cbp60g-1 snc2-1D and sard1-1 cpb60g-1 snc2-1D mutant plants. The expression was normalized with ACTIN1. Bars represent means \pm s.d $(n=3)$. (b) Free SA levels in the indicated genotypes. Bars represent means \pm s.d. $(n=4)$. Statistical differences among the samples are labelled with different letters (ANOVA, $P<0.01$ ). (c) Morphology of 3-week-old soil-grown plants of the indicated genotypes. Bar represents $1 \mathrm{~cm}$. (d,e) Expression levels of $P R 1$ (d) and PR2 (e) in the indicated genotypes as normalized by ACTIN1. Bars represent means $\pm \mathrm{s}$.d. ( $n=3$ ). (f) Quantification of $H$. arabidopsidis Noco2 sporulation on the indicated genotypes. Bars represent means \pm s.d. $(n=4)$. Statistical differences among the samples are labelled with different letters $(P<0.01$, one-way ANOVA; $n=3)$. Plants were grown on soil at $23^{\circ} \mathrm{C}$ and assayed 3 weeks after planting. ANOVA, analysis of variance.

induced by pathogen infection (Table 1). Distribution of sequence reads in the promoter and coding regions of these known defence regulators are shown in Supplementary Fig. 2.

One of the candidate target genes of SARD1 identified by ChIP-seq is WRKY70 (Table 1), which is known to regulate SAindependent defence responses in snc2-1D (ref. 26). Quantitative PCR analysis of the DNA immunoprecipitated by the anti-HA antibody confirmed that WRKY70 is a binding target of SARD1 (Fig. 2a). In sard 1 cpb60g mutant plants expressing the CBP60gHA fusion protein under its native promoter, pathogen-induced ICS1 expression was restored to similar level as in the sard1 single mutant, suggesting that CBP60g-HA functions similarly as wildtype protein (Supplementary Fig. 1). To determine whether WRKY70 is also a binding target of CBP60g, we carried out ChIPPCR experiments on transgenic plants expressing a CBP60g-HA fusion protein under its own promoter using the anti-HA antibody. As shown in Fig. 2b, CBP60g is also targeted to the promoter region of WRKYTO.
Next we analysed the expression of WRKY70 in snc2-1D, sard1-1 snc2-1D, cbp60g-1 snc2-1D and sard1-1 cbp60g-1 snc2-1D mutant plants. As shown in Fig. 2c, WRKY70 is expressed at a considerably higher level in snc2-1D than in wild type. The expression of WRKY70 is slightly lower in cbp60g-1 snc2-1D and clearly reduced in sard1-1 snc2-1D compared with snc2-D. However, it is further reduced to below wild-type level in the sard1-1 cbp60g-1 snc2-1D triple mutant (Fig. 2c). These data suggest that SARD1 and CBP60g have overlapping functions in regulating the expression of WRKY70 and that reduced expression of WRKY70 is at least partly responsible for the suppression of the snc2-1D-mediated SA-independent constitutive defence responses in the sard1-1 cbp60g-1 snc2-1D triple mutant.

SARD1 and CBP60g regulate the expression of EDS5 and NPR1. EDS5 is involved in pathogen-induced SA synthesis ${ }^{5,7}$. Analysis of the SARD1 ChIP-seq data revealed that EDS5 is a potential target gene of SARD1 as well (Table 1). A peak with a 
Table 1 | Known defence regulators identified as candidate target genes of SARD1 by ChIP-sequencing.

\section{AGI number}

AT3G56400

AT1G74710

AT4G39030

AT1G64280

AT1G19250

AT2G13810

AT5G13320

AT3G48090

AT3G52430

AT1G33560

AT4G33300

AT5G04720

AT4G33430

AT2G13790

AT4G34460

AT2G39660

AT4G08500

AT1G51660

AT3G45640

AT4G09570

AT3G46510

AT1G80840

AT2G25000

AT2G04450

AT4G12720

AT1G11310

AT5G61900

AT3G61190

AT2G45760
Protein name

Peak height

WRKY DNA-BINDING PROTEIN 70 (WRKY70)

ISOCHORISMATE SYNTHASE 1 (ICS1)

ENHANCED DISEASE SUSCEPTIBILITY 5 (EDS5)

110

NON-EXPRESSOR OF PATHOGENESIS-RELATED GENES 1 (NPR1)

163

99

AGD2-LIKE DEFENCE RESPONSE PROTEIN 1 (ALD1)

avrPphB SUSCEPTIBLE 3 (PBS3)

ENHANCED DISEASE SUSCEPTIBILITY 1 (EDS1)

PHYTOALEXIN DEFICIENT 4 (PAD4)

ACTIVATED DISEASE RESISTANCE 1 (ADR1)

ADR1-LIKE 1 (ADR1-L1)

ADR1-LIKE 2 (ADR1-L2)

BRI1-ASSOCIATED RECEPTOR KINASE 1 (BAK1)

BAK1-LIKE 1 (BKK1)

ARABIDOPSIS G PROTEIN $\beta$-SUBUNIT 1 (AGB1)

BOTRYTIS-INDUCED KINASE 1 (BIK1)

MAPK/ERK KINASE KINASE 1 (MEKK1)

MITOGEN-ACTIVATED PROTEIN KINASE KINASE 4 (MKK4)

MITOGEN-ACTIVATED PROTEIN KINASE 3 (MPK3)

CALCIUM-DEPENDENT PROTEIN KINASE 4 (CPK4)

PLANT U-BOX 13 (PUB13)

WRKY DNA-BINDING PROTEIN 40 (WRKY40)

WRKY DNA-BINDING PROTEIN 60 (WRKY60)

NUCLEOSIDE DIPHOSPHATE LINKED TO SOME MOIETY X 6 (NUDT6)

NUCLEOSIDE DIPHOSPHATE LINKED TO SOME MOIETY $X 7$ (NUDT7)

MILDEW RESISTANCE LOCUS O 2 (MLO2)

BONZAI 1 (BON1)

BON ASSOCIATION PROTEIN 1 (BAP1)

BON ASSOCIATION PROTEIN 2 (BAP2)
138

199

258

137

117

324

230

134

190

200

99

135

141

264

104

207

97

138

107

169

100

151

215

314

AG1, Arabidopsis Genome Initiative; ChIP, chromatin immunoprecipitation; SARD1, SAR DEFICIENT1.

height of 110 was identified $\sim 700 \mathrm{bp}$ upstream of the translation start site of EDS5. ChIP-PCR experiments confirmed that SARD1 is targeted to the promoter region of EDS5 (Fig. 3a). Further ChIP-PCR analysis showed that CBP60g also binds to the promoter region of EDS5 (Fig. 3b). To determine whether SARD1 and CBP60g are required for the induction of EDS5 by Pseudomonas syringae pv. maculicola (P.s.m.) ES4326, we compared the expression levels of EDS5 in wild type and sard11 cbp60g-1 plants. As shown in Fig. 3c, induction of EDS5 by P.s.m. ES4326 is greatly reduced in the sard1-1 cbp60g-1 double mutant. These data suggest that SARD1 and CBP60g directly regulate pathogen-induced expression of EDS5.

Another candidate target gene of SARD1 identified by ChIP-seq is NPR1, which encodes a putative SA receptor ${ }^{11}$. A peak with a height of 163 was identified $\sim 100 \mathrm{bp}$ upstream of the translation start site of NPR1 (Table 1). Binding of SARD1 to the promoter region of NPR1 was confirmed by ChIP-PCR (Fig. 3d). As shown in Fig. 3e, CBP60g is also targeted to the promoter region of NPR1. Analysis of the expression levels of NPR1 in wild type and sard1-1 cbp60g-1 plants showed that induction of NPR1 by P.s.m. ES4326 is compromised in the sard1-1 cbp60g-1 double mutant (Fig. 3f). These data suggest that SARD1 and CBP60g also regulate pathogen-induced expression of NPR1.

Multiple SAR regulators are targets of SARD1 and CBP60g. In addition to EDS5 and NPR1, three other genes required for SAR, $F M O 1, A L D 1$ and $P B S 3$, were identified as candidate target genes of SARD1 from the ChIP-seq data. The height of the peaks identified in the promoter regions of FMO1, ALD1 and PBS3 are 99, 138 and 199, respectively (Table 1). Binding of SARD1 to the promoters of these three genes was confirmed by ChIP-PCR experiments (Fig. 4a). Further ChIP-PCR analysis showed that
CBP60g also binds to the promoters of these genes (Fig. 4b). Consistent with data from previous gene expression studies ${ }^{25,28}$, we also observed dramatic reduction in bacteria-induced expression of FMO1, ALD1 and PBS3 in the sard1-1 cbp60g-1 double mutant (Fig. 4c). These data suggest that SARD1 and CBP60g directly regulate the expression of FMO1, ALD1 and $P B S 3$ in plant defence responses.

SARD1 and CBP60g target positive regulators of ETI ENHANCED DISEASE SUSCEPTIBILITY 1 (EDS1) and PHYTOALEXIN DEFICIENT 4 (PAD4) encode positive regulators of defence responses activated by TIR-NB-LRR $\mathrm{R}$ proteins ${ }^{29-33}$. NDR1 is required for defence responses activated by CC-NB-LRR $\mathrm{R}$ proteins ${ }^{29,34}$. EDS1 and PAD4, but not NDR1, were identified as candidate target genes of SARD1 by ChIP-seq (Table 1). The height of the peaks identified in the promoter regions of EDS1 and PAD4 are 258 and 137, respectively. ChIP-PCR experiments showed that SARD1 was targeted to the promoter regions of EDS1 and PAD4, but not NDR1 (Fig. 5a). In addition, CBP60g is also targeted to the promoters of EDS1 and PAD4, but not NDR1 (Fig. 5b). Quantitative RT-PCR was subsequently carried out to determine whether induction of the expression of EDS1 and PAD4 by bacterial infections is dependent on SARD1 and CBP60g. As shown in Fig. 5c, induction of EDS1 and PAD4 by P.s.m. ES4326 is markedly reduced in the sard1-1 cbp60g-1 double mutant. These data suggest that induction of EDS1 and PAD4 following pathogen infection is directly regulated by SARD1 and CBP60g.

$A D R 1, A D R-L 1$ and $A D R-L 2$ encode three closely related CC-NB-LRR proteins required for immunity mediated by TIR-NB-LRR R proteins RPP2 and RPP4 (ref. 35). They were also identified as candidate target genes of SARD1 by ChIP-seq (Table 1). The heights of the peaks identified in the promoter regions of $A D R 1, A D R-L 1$ and $A D R-L 2$ are 117, 324 and 230, 
a

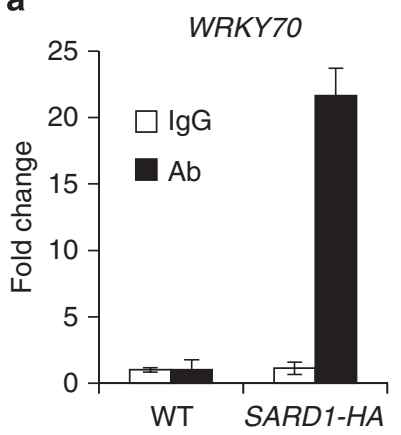

b

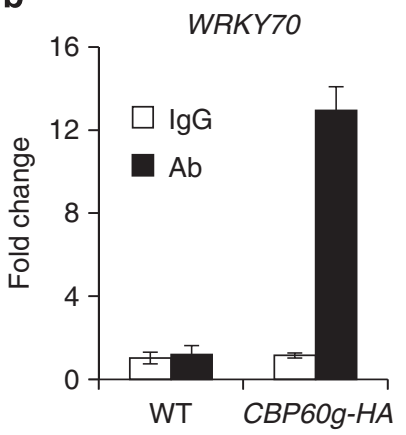

C

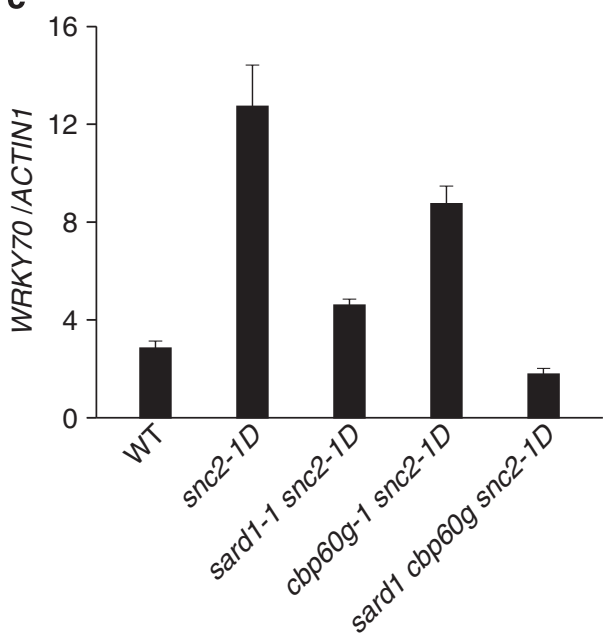

Figure 2 | SARD1 and CBP60g regulate the expression of WRKY70.

$(\mathbf{a}, \mathbf{b})$ Binding of SARD1 (a) and CBP60g (b) to the promoter of WRKY70 as determined by ChIP-PCR. Leaves of 25-day-old wild-type plants and SARD1$H A(\mathbf{a})$ or $C B P 60 g-H A(\mathbf{b})$ transgenic plants were infiltrated with P.s.m. ES4326 $\left(\mathrm{OD}_{600}=0.001\right) 24 \mathrm{~h}$ before collecting and cross-linking with $1 \%$ formaldehyde. SARD1-HA and CBP60g-HA chromatin complexes were immunoprecipitated with an anti-HA antibody and protein $\mathrm{A}$ agarose beads. Negative control reactions were performed in parallel using immunoglobin G (IgG). Immunoprecipitated DNA samples were quantified by real-time qPCR using primers specific to WRKY70 promoter. ChIP results are presented as fold changes by dividing signals from ChIP with the anti-HA antibody by lgG controls, which are set as one. Bars represent means \pm s.d. $(n=3)$. (c) WRKY70 expression in the indicated genotypes as normalized with ACTIN1. Bars represent means \pm s.d. $(n=3)$. qPCR, quantitative PCR.

respectively. ChIP-PCR analysis confirmed that SARD1 binds to the promoter regions of these three genes (Fig. $5 \mathrm{~d}$ ). ChIP-PCR experiments showed that CBP60g is also targeted to the promoter regions of $A D R 1, A D R-L 1$ and $A D R-L 2$ (Fig. $5 \mathrm{e}$ ). As shown in Fig. 5f, the expression of $A D R 1, A D R-L 1$ and $A D R-L 2$ is induced by P.s.m. ES4326 and the induction is partially dependent on SARD1 and CBP60g. These data suggest that SARD1 and CBP60g are likely to directly regulate the expression of $A D R 1, A D R-L 1$ and $A D R-L 2$ in plant defence.

SARD1 and CBP60g play critical roles in PTI. Among the candidate target genes of SARD1 identified by ChIP-seq, eight genes including BAK1, BKK1, AGB1, BIK1, MEKK1, MKK4, $M P K 3$ and CPK4 (Table 1) were previously shown to encode positive regulators of PTI (refs 36-48). Binding of SARD1 to the promoter regions of these genes was further confirmed by ChIP-PCR (Fig. 6a). In addition, CBP60g is also targeted to the promoter regions of these genes (Fig. 6b). As shown in Fig. 6c, expression of $B A K 1, B K K 1, A G B 1, B I K 1, M E K K 1, M K K 4, M P K 3$ and CPK4 is induced P.s.m. ES4326 and the induction is reduced in the sard1-1 cbp60g-1 double mutant, suggesting that SARD1 and CBP60g may directly regulate their expression in plant defence responses.

To test whether SARD1 and CBP60g are required for PTI, we analysed bacterial growth in wild type, sard1-1, cbp60g-1 and sard1-1 cbp60g-1 plants pretreated with flg22, a peptide from bacterial flagellin that is recognized by FLAGELLIN-SENSITIVE 2 (FLS2) (ref. 49). As shown in Fig. 6d, flg22-induced resistance to $P$. syringae pv tomato DC3000 is not obviously affected in the sard1-1 and cbp60g-1 single mutants, but clearly reduced in the sard1-1 cbp60g-1 double mutant, suggesting that SARD1 and CBP60g contribute to PTI.

SARD1 and CBP60g target negative regulators of defence. Analysis of the SARD1 ChIP-seq data also identified a number of negative regulators of plant immunity including $P U B 13$, WRKY40, WRKY60, NUDT6, NUDT7, MLO2, BON1, BAP1 and $B A P 2$ as candidate target genes of SARD1 (Table 1). Binding of SARD1 to the promoter regions of PUB13, WRKY40, WRKY60, NUDT6, NUDT7, MLO2, BON1, BAP1 and BAP2 was confirmed by ChIP-PCR analysis (Fig. 7a). In addition, CBP60g was also found to target the promoter regions of these nine genes (Fig. 7b). Quantitative RT-PCR analysis showed that the expression of PUB13, WRKY40, WRKY60, NUDT6, NUDT7, MLO2, BON1, $B A P 1$ and BAP2 are all induced by P.s.m. ES4326 and the induction is either reduced or blocked in the sard1-1 cbp60g-1 double mutant (Fig. 7c). These data suggest that SARD1 and CBP60g regulate the expression of these negative regulators of plant immunity during plant defence.

SARD1 regulates gene expression through the GAAATTT element. Previously, we showed that SARD1 and CBP60g bind preferentially to the oligonucleotide probe GAAATTTTGG (ref. 24). Bioinformatics analysis showed that the GAAATTT motif within this probe is over-represented in the promoters of the genes with SARD1 and CBP60g-dependent expression ${ }^{25}$. Analysis of the 1,902 candidate target genes of SARD1 in Supplementary Data 1 showed that the GAAATTT motif is also over-represented in the promoter regions of this group of genes $\left(P<10^{-15}\right.$, Fisher's exact test). This motif is over-represented in the promoter regions of 29 confirmed target genes of SARD1 and CBP60g listed in Table $1(P<0.005$, Fisher's exact test $)$ as well. However, not every gene in this group contains this motif in their promoter region. It is likely SARD1 and CBP60g can also bind to certain variants of the GAAATTT motif. Interestingly, a closely related sequence motif, G(A/T)AATT(T/G), was identified as a conserved motif $\left(P<10^{-25}\right.$, Fisher's exact test $)$ among the sequence peaks of genes in Supplementary Data 1 using the motif discovery algorithm DREME.

To test whether SARD1 activates its target gene expression through the GAAATTT motif, we made a construct expressing the luciferase reporter gene under the control of a $56 \mathrm{bp}$ fragment from the ChIP-Seq peak region in the promoter of ICS1, which contains a GAAATTT and a related GAAATT motif (Fig. 8a). Two additional constructs containing mutations in these two motifs were also created to determine whether they are required for activation of reporter gene expression by the $56 \mathrm{bp}$ fragment. These reporter gene constructs were transformed into Arabidopsis protoplasts to exam the luciferase reporter expression levels. As shown in Fig. 8b, all three constructs expressed similar levels of luciferase as the original NOS101-Luc vector, suggesting that the 56 bp promoter fragment cannot activate luciferase expression on its own in protoplast transient assays. However, when the 
a

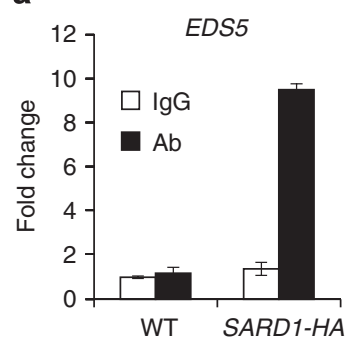

b

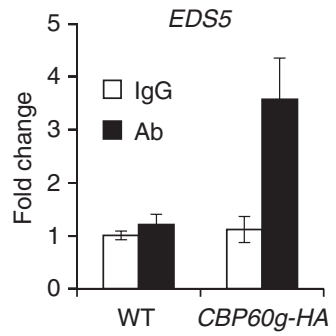

e

d

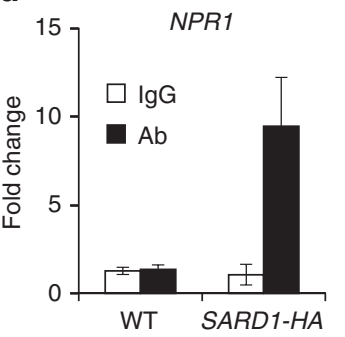

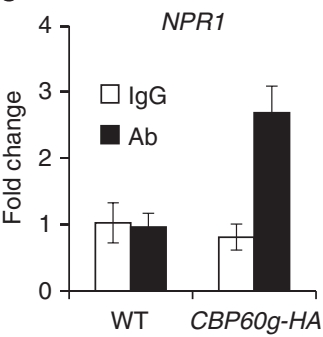

C

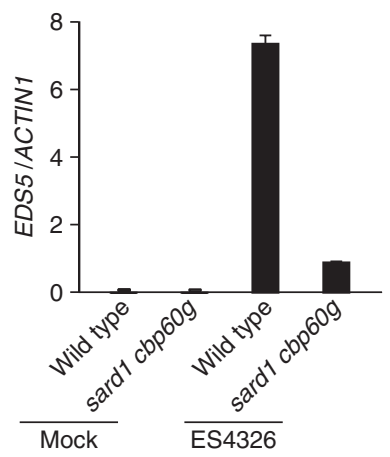

f

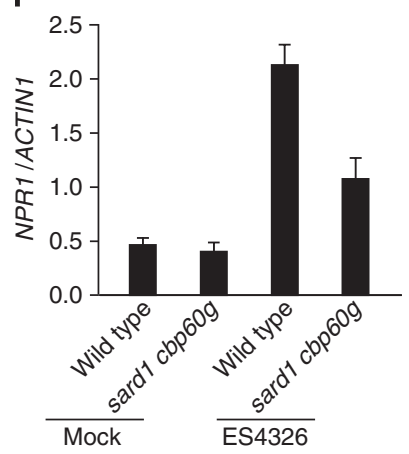

Figure 3 | EDS5 and NPR1 are direct binding targets of SARD1 and CBP60g. (a,b) Recruitment of SARD1-HA (a) and CBP60g-HA (b) to EDS5 promoter after P.s.m. ES4326 infection as determined by ChIP-PCR. ChIP was performed as described in Fig. 2. Real-time PCR was carried out using primers specific to EDS5 promoter. ChIP results are presented as fold changes by dividing signals from ChIP with the anti-HA antibody by those of IgG controls, which are set as one. Bars represent means \pm s.d. $(n=3)$. (c) Induction of EDS5 expression in wild type and sard1-1 cpb60g-1 by P.s.m. ES4326. Leaves of 25-day-old plants were infiltrated with P.s.m. ES4326 $\left(\mathrm{OD}_{600}=0.001\right)$ or $10 \mathrm{mM} \mathrm{MgCl}_{2}$ (mock) $12 \mathrm{~h}$ before collection for RT-PCR analysis. Bars represent means \pm s.d. $(n=3)$. (d,e) Recruitment of SARD1-HA (d) and CBP60g-HA (e) to the promoter of NPR1 after treatment with P.s.m. ES4326. ChIP and data analysis were carried out similarly as in $\mathbf{a}$ and $\mathbf{b}$. Bars represent means \pm s.d. $(n=3)$. (f) Induction of NPR1 expression by P.s.m. ES4326 in wild-type and sard7-1 cpb60g-1 double mutant plants. Samples were collected $12 \mathrm{~h}$ after infiltration with P.s.m. ES4326 $\left(\mathrm{OD}_{600}=0.001\right)$ or $10 \mathrm{mM} \mathrm{MgCl} 2(\mathrm{mock})$. Bars represent means \pm s.d. $(n=3)$.

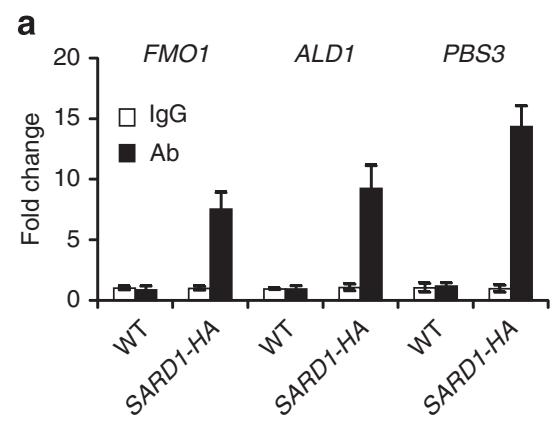

b
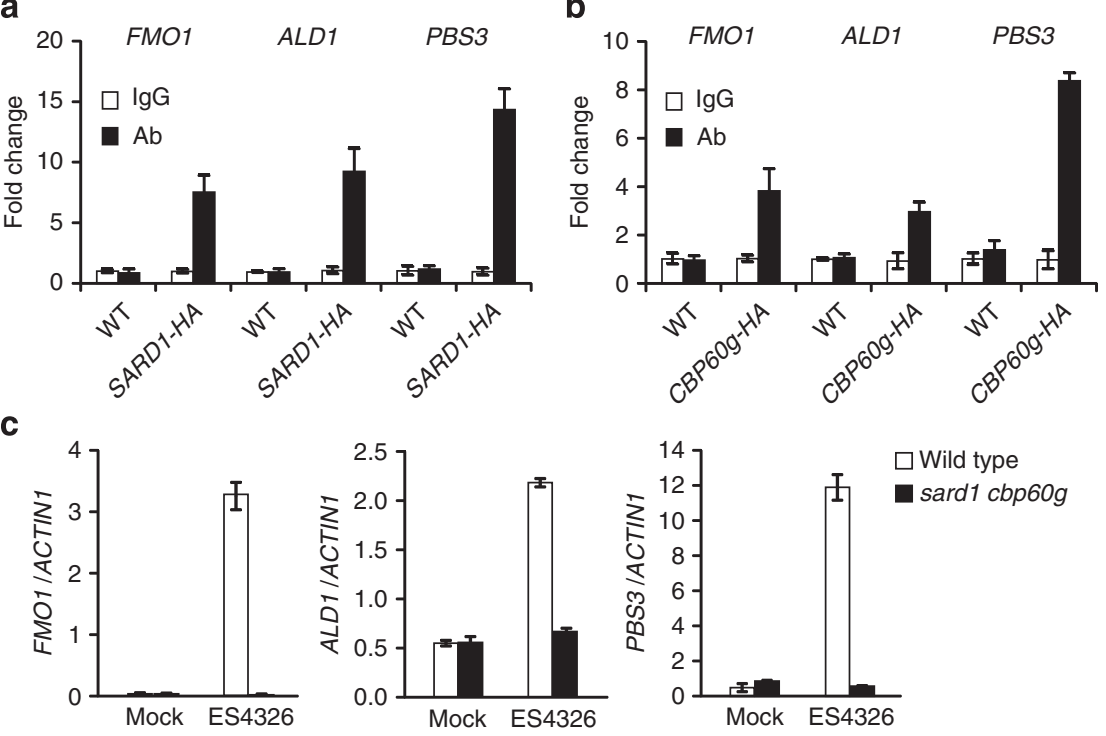

Figure 4 | SARD1 and CBP60g target genes essential for SAR. (a,b) Binding of SARD1-HA (a) and CBP60g-HA (b) to the promoter regions of FMO1, ALD1 and PBS3 following infection by P.s.m. ES4326 as determined by ChIP-PCR. ChIP was performed as described in Fig. 2. Real-time PCR was carried out using gene-specific primers. ChIP results are presented as fold changes by dividing signals from ChIP with the anti-HA antibody by those of the IgG control, which are set as one. Bars represent means \pm s.d. $(n=3)$. (c) Induction of the expression of FMO1, ALD1 and PBS3 by P.s.m. ES4326 infection. Samples were collected $12 \mathrm{~h}$ after inoculation with P.s.m. ES4326 $\left(\mathrm{OD}_{600}=0.001\right)$ or $10 \mathrm{mM} \mathrm{MgCl} 2$ (mock). Expression levels were normalized with ACTIN1. Bars represent means \pm s.d. $(n=3)$. 
a

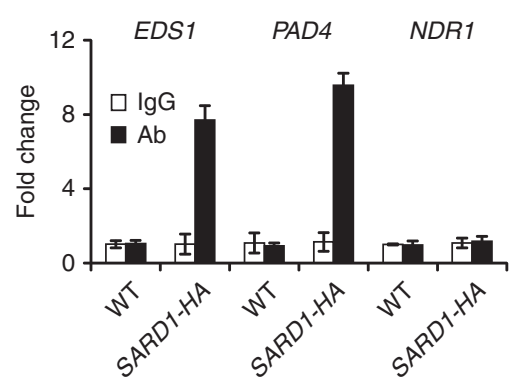

b

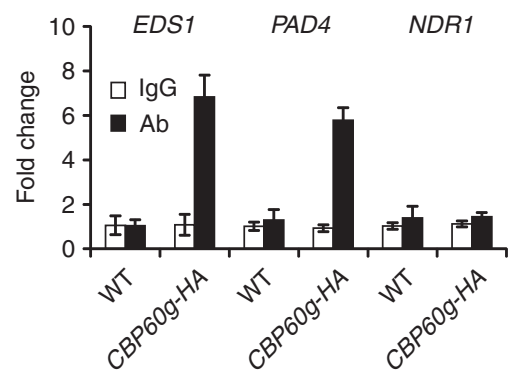

d

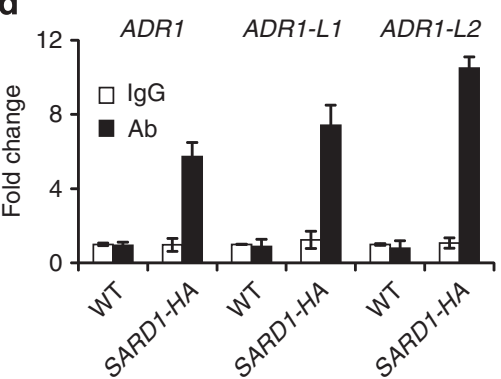

e

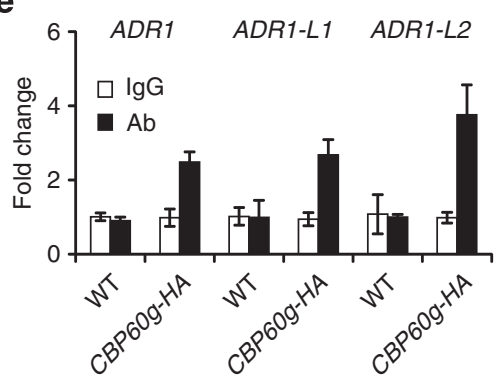

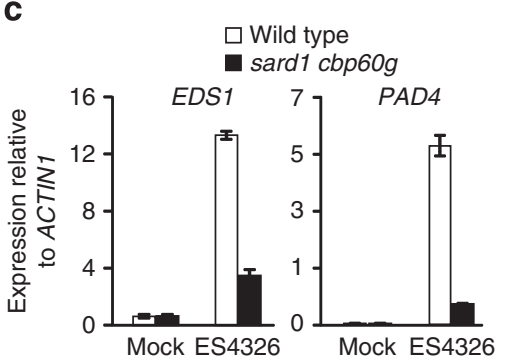

f
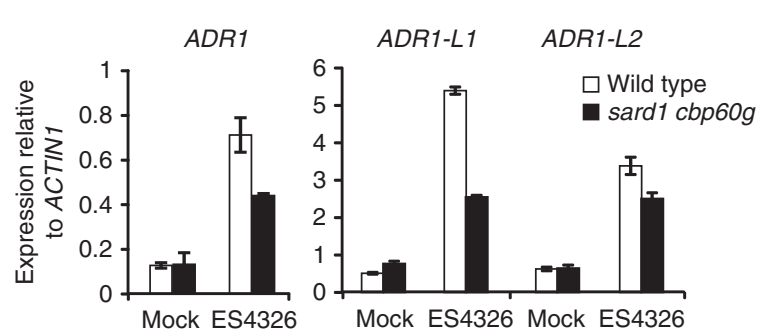

Figure 5 | SARD1 and CBP60g regulate the expression of positive regulators of ETI. (a,b) Binding of SARD1-HA (a) and CBP60g-HA (b) to promoter regions of EDS1 and PAD4 following infection by P.s.m. ES4326 as determined by ChIP-qPCR. NDR1 is not a direct target of SARD1 or CPB60g and is used as negative control. ChIP was performed as described in Fig. 2. Real-time PCR was carried out using primers specific to EDS1, PAD4 and NDR1 promoters. ChIP results are presented as fold changes by dividing signals from ChIP with the anti-HA antibody by those of the IgG controls, which are set as one. Bars represent means \pm s.d. $(n=3)$. (c) Induction of EDS1 and PAD4 expression in wild type and sard1-1 cpb60g-1 plants after P.s.m. ES4326 infection. Expression levels were normalized with ACTIN1. Bars represent means \pm s.d. $(n=3)$. (d,e) Binding of SARD1-HA (d) and CBP60g-HA (e) to the promoter regions of ADR1, ADR1-L1 and ADR1-L2 following infection by P.s.m. ES4326 as determined by ChIP-PCR. ChIP and data analysis were carried out similarly as in a and $\mathbf{b}$. Bars means \pm s.d. $(n=3)$. (f) Induction of ADR1, ADR1-L1 and ADR1-L2 expression by P.s.m. ES4326 as determined by real-time RT-PCR. Samples were collected $12 \mathrm{~h}$ after inoculation with P.s.m. ES4326 $\left(\mathrm{OD}_{600}=0.001\right)$ or $10 \mathrm{mM} \mathrm{MgCl} 2$ (mock). Expression levels were normalized with $A C T I N 1$. Bars represent means \pm s.d. $(n=3)$. qPCR, quantitative PCR.

luciferase reporter gene constructs were co-transformed together with a plasmid expressing the SARD1 protein into protoplasts, luciferase expression was much higher in samples transformed with the construct containing the wild-type $56 \mathrm{bp}$ promoter fragment compared with samples transformed with the NOS101Luc vector (Fig. 8c). In comparison, samples transformed with the construct carrying mutations in the GAAATTT motif exhibited significantly reduced luciferase activity. When both the GAAATTT and GAAATT motifs were mutated, the luciferase activity was further reduced to a level similar to that in the NOS101-Luc vector control. Together, these data suggest that SARD1 activates gene expression through GAAATTT or similar DNA sequence elements.

\section{Discussion}

SA functions as a key signalling molecule in SAR. SARD1 and CBP60g have previously been shown to regulate pathogen-induced SA synthesis ${ }^{23-25}$. In this study, we showed that, in addition to ICS1, the expression of another regulator of SA synthesis, EDS5, is also likely controlled by SARD1 and CBP60g.
NPR1, a gene required for the perception of SA by plants, is a target of SARD1 and CBP60g as well. Moreover, SARD1 and CBP60g also regulate pathogen-induced expression of several other genes required for SAR. Both SARD1 and CBP60g are targeted to the promoter regions of FMO1, ALD1 and PBS3 and induction of these genes by P.s.m. ES4326 is markedly reduced in the sard 1 cbp $60 \mathrm{~g}$ double mutant. These data suggest that SARD1 and CBP60g function in coordinating the induction of SAR regulators during plant defence.

Several defence regulators that function upstream of SA synthesis are also regulated by SARD1 and CBP60g. Both PAD4 and EDS1 are required for pathogen-induced SA synthesis ${ }^{32,50}$. SARD1 and CBP60g are targeted to their promoters and are required for their induction by P.s.m. ES4326. In addition, $A D R 1, A D R 1-L 1$ and $A D R 1-L 2$, three helper R genes required for pathogen-induced SA synthesis ${ }^{35}$, are also targets of SARD1 and CBP60g. Regulation of the induction of PAD4, EDS1, ADR1, ADR1-L1 and ADR1-L2 by SARD1 and CBP60g may play critical roles in promoting SA synthesis during pathogen infection. 


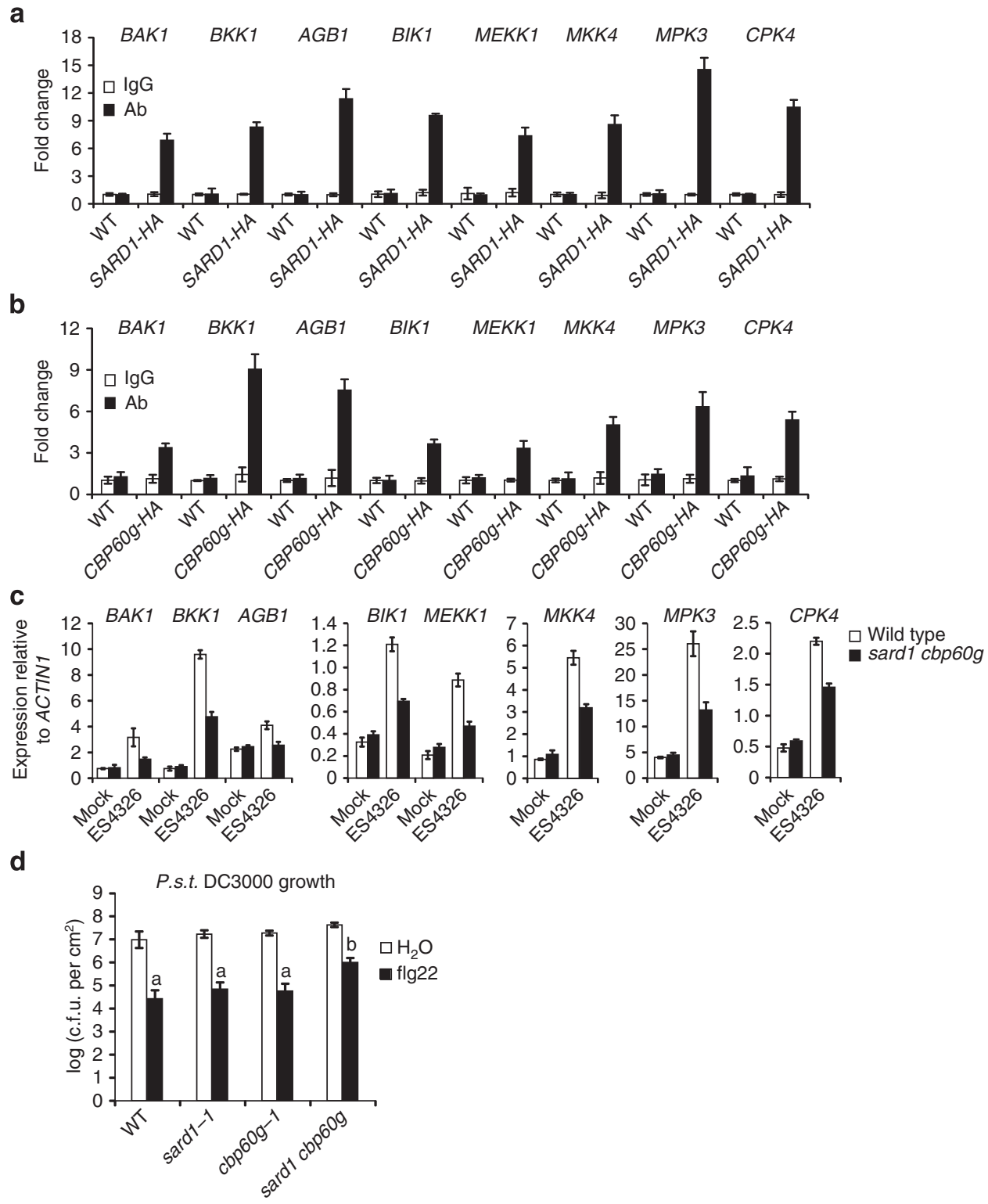

Figure 6 | SARD1 and CBP60g modulate the expression of signalling components of PTI and contribute to flg22-induced resistance to P.s.t. DC3000. $(\mathbf{a}, \mathbf{b})$ Binding of SARD1-HA (a) and CPB60g-HA (b) to the promoter regions of BAK1, BKK1, AGB1, BIK1, MEKK1, MKK4, MPK3 and CPK4 following P.s.m. ES4326 infection as determined by ChIP-PCR. ChIP was performed as described in Fig. 2. Real-time PCR was carried out using gene-specific primers. ChIP results are presented as fold changes by dividing signals from ChIP with the anti-HA antibody by those of the IgG controls, which are set as one. Bars represent means \pm s.d. $(n=3)$. (c) Induction of BAK1, BKK1, AGB1, BIK1, MEKK1, MKK4, MPK3 and CPK4 expression by P.s.m. ES4326 as determined by realtime RT-PCR. Samples were collected $12 \mathrm{~h}$ after inoculation with P.s.m. ES4326 (OD $600=0.001)$ or $10 \mathrm{mM} \mathrm{MgCl} 2$ (mock). Expression levels of the genes were normalized with ACTIN1. Bars represent means \pm s.d. $(n=3)$. (d) flg22-induced resistance to P.s.t DC3000 on the indicated genotypes. Four-week-old plants were infiltrated with $1 \mu \mathrm{M}$ flg22 or $\mathrm{H}_{2} \mathrm{O} 1$ day before inoculation with P.s.t. $\mathrm{DC} 3000\left(\mathrm{OD}_{600}=0.001\right)$. Bacterial growth was determined 3 days post inoculation. Bars represent means \pm s.d. $(n=5)$. Statistical differences among the samples are labelled with different letters (ANOVA, $P<0.001)$. ANOVA, analysis of variance; c.f.u., colony-forming unit; P.s.t., P. syringae pv tomato.

We also found that SARD1 and CBP60g function downstream of the receptor-like protein SNC2 to regulate both SA-dependent and SA-independent defence pathways. SARD1 and CBP60g are required for the increased expression of ICS1 and SA synthesis in snc2-1D. Regulation of the SA-independent defence pathway by SARD1 and CBP60g appears to be at least partly through their control of WRKY70 expression, a key regulator of the SA-independent defence responses in snc2-1D (ref. 26), as both SARD1 and CBP60g are targeted to the promoter of WRKY70 and are required for the induction of WRKY70 in snc2-1D.
Furthermore, a large number of genes encoding regulatory components of PTI are binding targets of SARD1 and CBP60g and require SARD1 and CBP60g for induction by bacterial infection. Among them, BAK1 and BKK1 serve as co-receptors of FLS2 and EF-TU RECEPTOR (EFR) (refs 36-38). BIK1 and AGB1 function downstream of multiple PAMP receptors to regulate ROS production and defence against pathogen infection $^{39-45}$. MEKK1, MKK4 and MPK3 are components of MAP kinase cascades downstream of PAMP receptors ${ }^{47,51-54}$. CPK4 was identified as a calcium dependent protein kinase downstream of FLS2 (ref. 48). The critical role of SARD1 and 
a

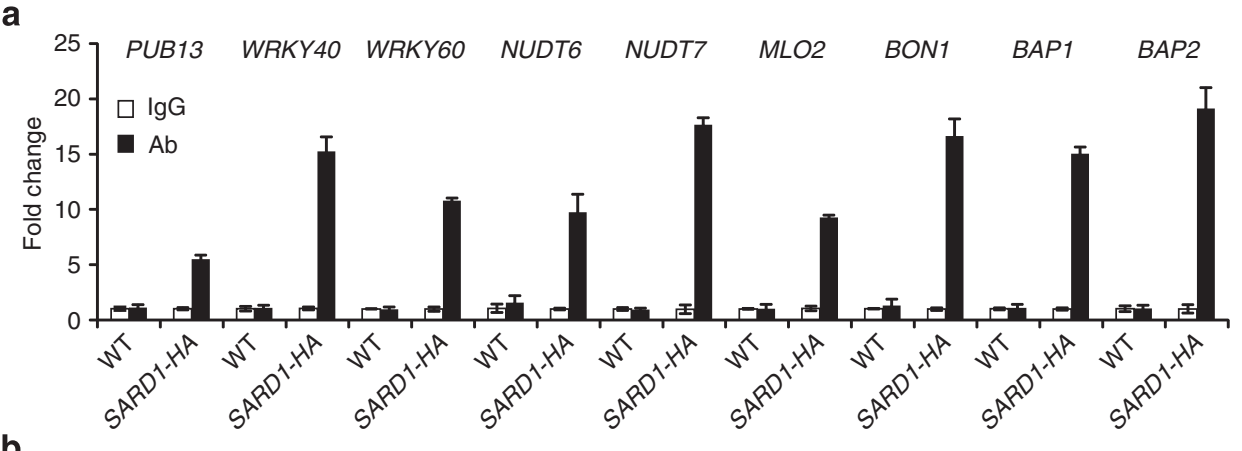

b

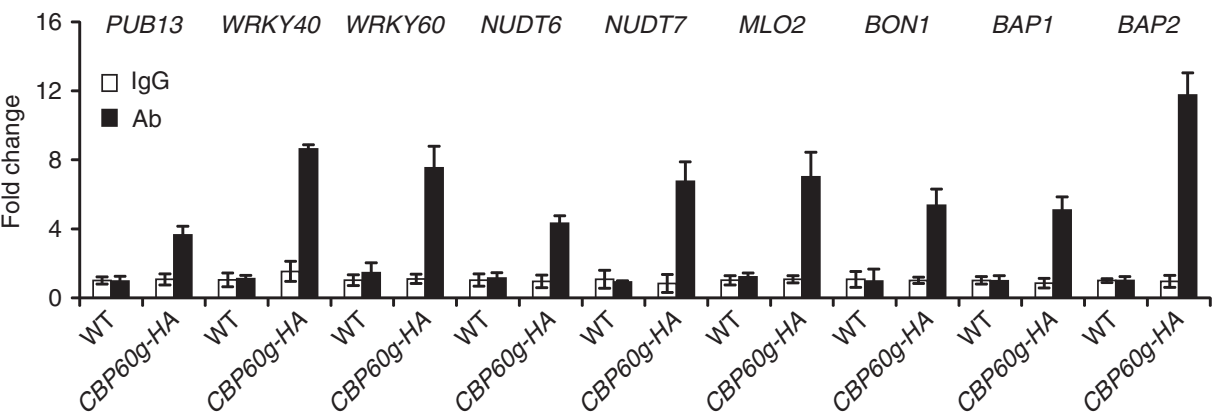

C

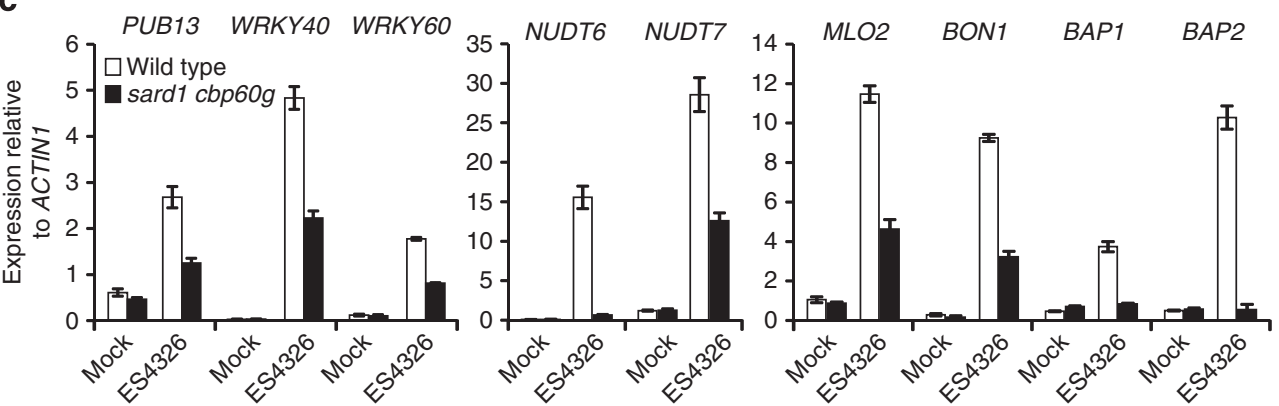

Figure 7 | SARD1 and CBP60g modulate the expression of genes encoding negative regulators of plant defence. (a,b) Recruitment of SARD1-HA (a) and CBP60g-HA (b) to the promoter regions of PUB13, WRKY40, WRKY60, NUDT6, NUDT7, MLO2, BON1, BAP1 and BAP2 following P.s.m. ES4326 infection as determined by ChIP-PCR. ChIP was performed as described in Fig. 2. Real-time PCR was carried out using gene-specific primers. ChIP results are presented as fold changes by dividing signals from ChIP with the anti-HA antibody by those of the lgG controls, which are set as one. Bars represent means \pm s.d. $(n=3)$. (c) Induction of PUB13, WRKY40, WRKY60, NUDT6, NUDT7, MLO2, BON1, BAP1 and BAP2 genes in wild type and sard1-1 cpb60g-1 by P.s.m. ES4326. Samples were collected $12 \mathrm{~h}$ after inoculation with P.s.m. ES4326 $\left(\mathrm{OD}_{600}=0.001\right)$ or $10 \mathrm{mM} \mathrm{MgCl}_{2}$ (mock). Expression levels of the genes were normalized with ACTIN1. Bars represent means \pm s.d. $(n=3)$.

CBP60g in PTI was further confirmed by the attenuation of flg22induced pathogen resistance in the sard 1 cbp60g double mutant.

In addition to upregulation of positive regulators, negative regulators are often induced during plant defence as well. Induction of negative regulators is critical for feedback inhibition of defence responses to prevent uncontrolled activation, which may lead to autoimmunity. We showed that a number of negative regulators of plant immunity including PUB13, WRKY40, WRKY60, NUDT6, NUDT7, MLO2, BON1, BAP1 and BAP2 are also targets of SARD1 and CBP60g. Among them, PUB13 is a U-box/ARM E3 ubiquitin ligase that regulates cell death as well as degradation of FLS2 after flagellin induction ${ }^{55,56}$; WRKY40 and WRKY60 function redundantly with their close homologue, WRKY18, to repress basal defence ${ }^{57,58}$; NUDT6 and NUDT7 are two Nudix domain-containing proteins that negatively regulate EDS1-dependent immune responses ${ }^{13,59,60}$; MLO2 functions as a negative regulator of resistance to powdery mildew ${ }^{61}$; BON1 functions as a negative regulator of immunity mediated by the TIR-NB-LRR R protein SNC1 (ref. 62); BAP1 and BAP2 encode two $\mathrm{C} 2$ domain-containing proteins that negatively regulate programmed cell death ${ }^{63,64}$. All these genes are induced following infection by P.s.m. ES4326 and their induction requires SARD1 and CBP60g, suggesting that SARD1 and CBP60g also play an important role in the negative feedback regulation of plant defence.

Bioinformatics analysis has previously been used to analyze genes that are co-expressed with a group of SARD1/CBP60gdependent genes ${ }^{28}$. Four genes including AGP5, At5g52760, $C M L 46$ and $C M L 47$ that form a small cluster with SARD1 and ICS1 were identified as candidate target genes of SARD1 and CBP60g. These genes are also identified as binding targets of SARD1 in our ChIP-seq data (Supplementary Data 1). EDS1 and PAD4 were also found to cluster with ICS1 in the co-expression analysis. They were placed upstream of SARD1 and CBP60g. Interestingly, both EDS1 and PAD4 have been shown to be targets of SARD1 and CBP60g in our ChIP studies. The commonly used defence marker genes $P R 1$ and $P R 2$ were also found in one of the clusters co-expressed with SARD1/CBP60g-dependent genes. However, both of them were not identified as binding targets of SARD1 in our ChIP-seq data, suggesting that they are not directly regulated by SARD1 and CBP60g. It is likely that genes co-expressed with SARD1/CBP60g-dependent genes include 
a

\begin{tabular}{rr|l|} 
NOS101-LUC & NOS101 & Luciferase \\
ICS1-56-NOS101-LUC & ICS1-56 & NOS101 \\
ICS1-56m-NOS101-LUC & ICS1-56m & NOS101 \\
ICS1-56m2-NOS101-LUC Luciferase \\
\hline
\end{tabular}

ICS1-56 gtgtaatttggtggttatttcatagaaattttggggaaattgttgcacctctccac ICS1-56m gtgtaatttggtggttatttcatagaagggttggggaaattgttgcacctctccac ICS1-56m2 gtgtaatttggtggttatttcatagaagggttggggaaggggttgcacctctccac b

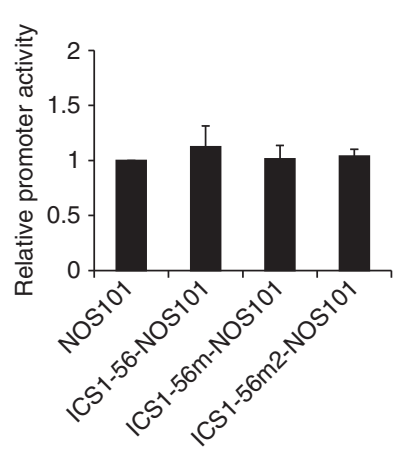

c

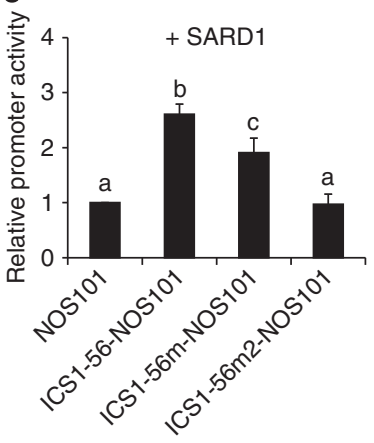

Figure 8 | SARD1 activates reporter gene expression through the GAAATTT motif. (a) Reporter constructs used in the promoter activity assay. NOS101, a basal promoter of the nopaline synthase gene ( -101 to +4); ICS1-56, a 56 bp fragment from the ChIP-Seq peak region in ICS1 promoter; ICS1-56m and ICS1-56m2, mutant versions of ICS1-56 with mutations (underlined) in the GAAATTT or GAAATT motif. The GAAATTT and GAAATT sequences are bolded. (b) Luciferase activities in protoplasts transformed with individual reporter constructs. (c) Luciferase activities in protoplasts transformed with individual reporter constructs together with a 35S-SARD1 plasmid. A 35S-Renilla Luciferase construct was included in all assays as an internal transformation efficiency control. The activities of luciferase were normalized with the expression of the Renilla luciferase and compared with the value obtained from protoplasts transfected with NOS101-LUC construct, which was set as 1. The error bars represent means \pm s.d. from three biological replicates.

genes that are either directly or indirectly regulated by SARD1 and CBP60g.

In summary, a large number of genes encoding key regulators of plant immunity are direct binding targets of SARD1 and CBP60g and their expression is modulated by SARD1 and CBP60g during plant defence. This is consistent with the functions of these two transcription factors in PTI, ETI and SAR. Based on this data we suggest that SARD1 and CBP60g orchestrate the induction of plant defence regulators in plant immunity (Fig. 9).

\section{Methods}

Plant materials and growth conditions. Arabidopsis sard1-1, cpb60g-1, sard1-1 cbp60g-1 and snc2-1D npr1-1 mutants and SARD1-HA and CBP6Og-HA transgenic plants were described previously ${ }^{24,26}$. The snc2-1D single mutant was identified from the F2 population of a cross between Col-0 and snc2-1D npr1-1. sard1-1 snc2$1 D, c p b 60 g-1$ snc2-1D and sard 1 cpb60g snc2-1D mutants were isolated from the F2 population of a cross between sard1-1 cpb60g-1 and snc2-1D npr1-1. Primers used for genotyping are listed in Supplementary Table 1. Plants were grown under long day conditions ( $16 \mathrm{~h}$ light per $8 \mathrm{~h}$ dark cycle) at $23^{\circ} \mathrm{C}$ unless otherwise specified.

Mutant analysis. To analyze gene expression in $s n c 2-1 D$, sard1-1 snc2-1D, $c b p 60 g$ 1 snc2-1D and sard 1 cbp60g snc2-1D, $50 \mathrm{mg}$ of leaves were collected from threeweek-old soil-grown plants for RNA isolation. To analyze gene expression after P.s.m. ES4326 infection, leaves of 25-day-old plants grown under short day conditions ( $12 \mathrm{~h}$ light per $12 \mathrm{~h}$ dark cycle) were infiltrated with P.s.m. ES4326 or $10 \mathrm{mM} \mathrm{MgCl}_{2} 12 \mathrm{~h}$ before sample collection. Four leaves from four individual
Pathogen infection

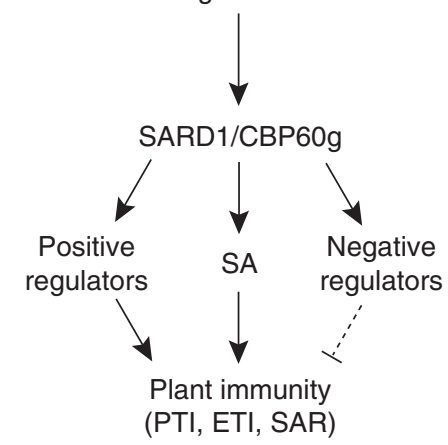

Figure 9 | Proposed scheme for regulation of plant defence responses by SARD1 and CBP60g. Following pathogen infection, SARD1 and CBP60g are activated. Subsequently, the expression of a large number of their target genes is turned on. Upregulation of positive regulators of PTI, ETI and SAR and increased SA synthesis lead to enhanced plant immunity against pathogens. Meanwhile, negative regulators of plant immunity are turned on to attenuate plant defence responses.

plants were mixed as one sample. RNA was isolated from three independent samples using EZ-10 Spin Column Plant RNA Mini-Preps Kit (Bio Basic, Canada) and subjected to subsequent RT-PCR analysis. Moloney Murine leukaemia virus reverse transcriptase was used for reverse transcription according to the manufacturer's instructions (New England Biolabs). Real-time PCR was performed using the SYBR Premix Ex Taq II (TAKARA). Primers used for real-time PCR were listed in Supplementary Table 1. ACTIN1 was used as an internal control.

SA was extracted and measured using a protocol modified from Li et al $l^{65}$ About $0.1 \mathrm{~g}$ of leaf tissue from 3-week-old soil-grown plants was collected and grounded in liquid nitrogen. Four samples for each genotype were collected and analysed. A volume of $0.6 \mathrm{ml}$ of $90 \%$ methanol was added to each sample and the samples were subsequently vortexed and sonicated for $20 \mathrm{~min}$. After spinning at $16,000 \mathrm{~g}$ for $20 \mathrm{~min}$, the supernatant was collected and the pellet was re-extracted with $0.5 \mathrm{ml}$ of $100 \%$ methanol as above. The supernatants from the two extractions were combined and dried by vacuum. A volume of $0.5 \mathrm{ml}$ of $5 \%$ trichloroacetic acid was then added to the dry samples and the samples were vortexed, sonicated for $5 \mathrm{~min}$, and centrifuged at $16,000 \mathrm{~g}$ for $15 \mathrm{~min}$. The supernatant was collected and extracted three times with $0.5 \mathrm{ml}$ of extraction medium (ethylacetate/cyclopentane/ isopropanol:100/99/1 by volume). After spinning at 16,000 $\mathrm{g}$ for $1 \mathrm{~min}$, the top organic phases were collected, combined and dried by vacuum. The samples were then re-suspended in $250 \mu \mathrm{l}$ of mobile phase ( $0.2 \mathrm{M} \mathrm{KAc}, 0.5 \mathrm{mM} \mathrm{EDTA}$ ( $\mathrm{pH} 5)$ ) by vortexing and sonicating for $5 \mathrm{~min}$. After spinning at $16,000 \mathrm{~g}$ for $5 \mathrm{~min}$, the supernatants were kept and analysed by high-performance liquid chromatography to determine the amount of SA.

H. arabidopsidis Noco2 infection assays were carried out on 3-week-old soilgrown plants by spraying plants with $H$. arabidopsidis Noco2 spore suspension at a concentration of 50,000 per ml water. Afterwards, plants were covered with a clean dome and grown at $18^{\circ} \mathrm{C}$ under $12 \mathrm{~h}$ light per $12 \mathrm{~h}$ dark cycle in a growth chamber. H. arabidopsidis Noco2 sporulation was scored 7 days later as previously described $^{66}$.

To assay for flg22-induced pathogen resistance, leaves of 4-week-old plants were infiltrated with $1 \mu \mathrm{M}$ of flg22 or $\mathrm{ddH}_{2} \mathrm{O}$ as control. After $24 \mathrm{~h}$, the same leaves were inoculated with $P$. syringae pv tomato DC3000 $\left(\mathrm{OD}_{600}=0.001\right)$ in $10 \mathrm{mM}$ $\mathrm{MgCl}_{2}$. Three days post inoculation, a leaf disc was taken from each infected leaf and two leaf discs from the same plant were collected as one sample. The samples were ground, diluted serially in $10 \mathrm{mM} \mathrm{MgCl}$, and plated on Lysogeny broth agar plates with $25 \mu \mathrm{g} \mathrm{ml}^{-1}$ rifampicin and $50 \mu \mathrm{g} \mathrm{ml}{ }^{-1}$ kanamycin. After incubation at $28^{\circ} \mathrm{C}$ for $36 \mathrm{~h}$, bacterial colonies were counted from selected dilutions and the colony numbers were used to calculate colony forming units.

ChIP analysis. For ChIP experiments, two to three fully expanded leaves of 25day-old plants grown under short day condition were infiltrated with P.s.m. ES4326 $\left(\mathrm{OD}_{600}=0.001\right)$. The inoculated leaves were collected after $24 \mathrm{~h}$. About $4 \mathrm{~g}$ of leaf tissue was cross-linked in $75 \mathrm{ml}$ of $1 \%$ formaldehyde solution plus $0.01 \%$ Silwet L-77 under vacuum for $20 \mathrm{~min}$. Glycine ( $2 \mathrm{M}$ ) was added to a final concentration of $0.125 \mathrm{M}$ and the sample was vacuumed for an additional $5 \mathrm{~min}$ to stop crosslinking. The tissue was rinsed three times with $60 \mathrm{ml}$ of cold $\mathrm{ddH}_{2} 0$ and dried with blotting paper. The nuclei were prepared as previously described ${ }^{67}$ and resuspended in $300 \mu \mathrm{l}$ of nuclei lysis buffer $(50 \mathrm{mM}$ Tris- $\mathrm{HCl}(\mathrm{pH} 8.0), 10 \mathrm{mM}$ EDTA, $1 \%$ SDS, $0.1 \mathrm{mM}$ PMSF, 1xPI). The nuclei suspensions were subsequently sonicated to shear the DNA to an average size of $0.3-1 \mathrm{~kb}$.

The sonicated chromatin suspension was spun at $12,000 \mathrm{~g}$ for $5 \mathrm{~min}$ at $4{ }^{\circ} \mathrm{C}$ to pellet debris. The supernatant was moved to a new $15 \mathrm{ml}$ tube. An aliquot of $5 \mu \mathrm{l}$ from each sample was moved into a clean $1.5 \mathrm{ml}$ Eppendorf tube and set aside 
at $-20^{\circ} \mathrm{C}$ as 'input'. ChIP dilution buffer $(3 \mathrm{ml} ; 1.1 \%$ Triton X-10, $1.2 \mathrm{mM}$ EDTA, $16.7 \mathrm{mM}$ Tris- $\mathrm{HCl}, \mathrm{pH} 8.0,167 \mathrm{mM} \mathrm{NaCl}$ ) was then added to the $15 \mathrm{ml}$ tube. For pre-clearing, $100 \mu \mathrm{l}$ of Protein A agarose beads balanced with the ChIP dilution buffer was added to the chromatin samples and kept at $4{ }^{\circ} \mathrm{C}$ for $1 \mathrm{~h}$ with rotation. The beads were pelleted at $2,400 \mathrm{~g}$ for 2 min and the supernatants were divided equally into two samples. A volume of $5 \mu \mathrm{l}\left(0.4 \mathrm{mg} \mathrm{ml}^{-1}\right)$ of anti-HA antibody (Roche) was added to one sample for immunoprecipitation and immunoglobin $G$ was added to the other sample as control. The samples were incubated overnight at $4^{\circ} \mathrm{C}$ with gentle agitation. Subsequently, $100 \mu \mathrm{l}$ of Protein A agarose beads balanced with ChIP dilution buffer was added to each sample and kept at $4{ }^{\circ} \mathrm{C}$ for $2 \mathrm{~h}$ with gentle agitation.

The Protein A beads were then pelleted by centrifugation at 2,400g for $10 \mathrm{~s}$ at $4{ }^{\circ} \mathrm{C}$. The beads were washed with low salt wash buffer $(150 \mathrm{mM} \mathrm{NaCl}, 0.1 \%$ SDS, $1 \%$ Triton X-100, 2 mM EDTA, $20 \mathrm{mM}$ Tris-HCl, pH 8.0), high salt wash buffer (500 mM NaCl, 0.1\% SDS, $1 \%$ Triton X-100, 2 mM EDTA, $20 \mathrm{mM}$ Tris-HCl, $\mathrm{pH}$ $8.0), \mathrm{LiCl}$ wash buffer $(0.25 \mathrm{M} \mathrm{LiCl}, 1 \% \mathrm{NP}-40,1 \%$ sodium deoxycholate, $10 \mathrm{mM}$ Tris- $\mathrm{HCl}, \mathrm{pH}$ 8.0, $1 \mathrm{mM}$ EDTA) and TE buffer sequentially. For each buffer, a quick wash by spinning at 2,400g for $10 \mathrm{~s}$ and a second wash with $5 \mathrm{~min}$ agitation were performed. A volume of $1 \mathrm{ml}$ of buffer was used in each wash.

After the final wash, the samples were pelleted for an additional $2 \mathrm{~min}$ at $2,400 \mathrm{~g}$ to remove the supernatant thoroughly. To elute the immune complexes, $250 \mu \mathrm{l}$ of Elution Buffer ( $1 \% \mathrm{SDS}, 0.1 \mathrm{M} \mathrm{NaHCO}_{3}$ ) was added to the beads. The samples were vortexed briefly and incubated at $65^{\circ} \mathrm{C}$ for $15 \mathrm{~min}$ with gentle agitation. After spinning at $3,800 \mathrm{~g}$ for $2 \mathrm{~min}$, the supernatant was carefully transferred to a fresh tube. The pellet was eluted one more time with $250 \mu \mathrm{l}$ of Elution Buffer and the two eluates were combined (a total of $\sim 500 \mu \mathrm{l}$ ). At the same time, $500 \mu \mathrm{l}$ of Elution Buffer was added to the input samples collected before immunoprecipitation. A volume of $1 \mu \mathrm{l}$ of $10 \mathrm{mg} \mathrm{ml}^{-1}$ DNase-free RNase A was added to each sample. After incubation at $37^{\circ} \mathrm{C}$ for $1 \mathrm{~h}, 10 \mu \mathrm{l}$ of $0.5 \mathrm{M}$ EDTA, $20 \mu \mathrm{l} 1 \mathrm{M}$ Tris- $\mathrm{HCl}(\mathrm{pH} 6.5)$ and $2 \mu \mathrm{l}$ of $10 \mathrm{mg} \mathrm{ml}^{-1}$ proteinase $\mathrm{K}$ were added to each sample. The samples were incubated at $45^{\circ} \mathrm{C}$ for $1 \mathrm{~h}$ and extracted with the same volume of Tris saturated phenol:chloroform:isoamyl alcohol $(25: 24: 1 \mathrm{v} / \mathrm{v})$ twice. DNA was then precipitated by adding 0.7 volume isoproponal, $1 / 10$ volume of $3 \mathrm{M} \mathrm{NaOAc}$ and $1 \mu \mathrm{l} 2 \mathrm{M}$ glycogen and incubating at room temperature for $30 \mathrm{~min}$. DNA was pelleted by spinning for $20 \mathrm{~min}$ at $16,700 \mathrm{~g}$. The DNA pellets were washed with $80 \%$ ethanol, dried at room temperature, re-suspended in $50 \mu \mathrm{l} \mathrm{TE}$ buffer, and stored at $-20^{\circ} \mathrm{C}$ for further use.

For ChIP-sequencing, DNA sequencing libraries were prepared from chromatin immunoprecipitated DNA using a library preparation kit (E6000s, New England Biolabs) according to the manufacturer's instructions and sequenced using an Illumina Genome Analyzer. Tissue from untreated SARD1-HA transgenic plants was used as the negative control. Sequence reads were mapped to Arabidopsis genome sequence using Bowtie 0.12.8 (ref. 68). Sequence coverage at each position on the genome was scored by Samtools ${ }^{69}$ and used to identify peaks in the genome. The 500 bp sequences centred on the peak summits shown in Supplementary Data 1 were used to identify conserved SARD-binding motifs using DREME (ref. 70). DREME was run with default settings and sequences from the promoter regions of randomly chosen genes were used as background control. Confirmation of ChIPseq results was carried out with three independent ChIP experiments. Independently grown plants were used in each repeat and immunoprecipitated DNA was quantified by real-time PCR using gene-specific primers. The primers used to amplify the promoter regions of the target genes are listed in

Supplementary Table 1. Real-time PCR was performed in 96-well format using Bio-Rad CFX connect Real-Time PCR systems and the SYBR Premix Ex Taq II (TAKARA).

Promoter activity assay. The NOS101-Luciferase reporter vector was created by modifying pGreen0229 to include a firefly luciferase gene driven by a basal promoter of the nopaline synthase gene ( -101 to +4 , designated NOS101). The wild type and mutant versions of the $56 \mathrm{bp}$ promoter fragment of ICS1 were synthesized and inserted upstream of the NOS101 basal promoter in the reporter vector. Promoter activity assays were performed by expressing the reporter constructs with the 35S-SARD1 construct or empty vector in Arabidopsis protoplasts. A 35S-driven Renilla luciferase reporter was included in the assays as internal transfection controls. Transformed protoplasts were incubated for $16-20 \mathrm{~h}$ before the activities of the luciferases were measured using a DualLuciferase Reporter Assay (Promega).

\section{References}

1. Monaghan, J. \& Zipfel, C. Plant pattern recognition receptor complexes at the plasma membrane. Curr. Opin. Plant Biol. 15, 349-357 (2012).

2. Jones, J. D. \& Dangl, J. L. The plant immune system. Nature 444, 323-329 (2006).

3. Durrant, W. E. \& Dong, X. Systemic acquired resistance. Annu. Rev. Phytopathol. 42, 185-209 (2004).

4. Vlot, A. C., Dempsey, D. A. \& Klessig, D. F. Salicylic Acid, a multifaceted hormone to combat disease. Annu. Rev. Phytopathol. 47, 177-206 (2009).

5. Nawrath, C. \& Metraux, J. P. Salicylic acid induction-deficient mutants of Arabidopsis express $P R-2$ and $P R-5$ and accumulate high levels of camalexin after pathogen inoculation. Plant Cell 11, 1393-1404 (1999).
6. Wildermuth, M. C., Dewdney, J., Wu, G. \& Ausubel, F. M. Isochorismate synthase is required to synthesize salicylic acid for plant defence. Nature 414, 562-565 (2001).

7. Rogers, E. E. \& Ausubel, F. M. Arabidopsis enhanced disease susceptibility mutants exhibit enhanced susceptibility to several bacterial pathogens and alterations in PR-1 gene expression. Plant Cell 9, 305-316 (1997).

8. Nawrath, C., Heck, S., Parinthawong, N. \& Metraux, J. P. EDS5, an essential component of salicylic acid-dependent signaling for disease resistance in Arabidopsis, is a member of the MATE transporter family. Plant Cell 14, 275-286 (2002).

9. Serrano, M. et al. Export of salicylic acid from the chloroplast requires the multidrug and toxin extrusion-like transporter EDS5. Plant Physiol. 162, 1815-1821 (2013).

10. Dong, X. NPR1, all things considered. Curr. Opin. Plant Biol. 7, 547-552 (2004).

11. Wu, Y. et al. The Arabidopsis NPR1 protein is a receptor for the plant defense hormone salicylic acid. Cell Rep. 1, 639-647 (2012).

12. Fu, Z. Q. et al. NPR3 and NPR4 are receptors for the immune signal salicylic acid in plants. Nature 486, 228-232 (2012).

13. Bartsch, M. et al. Salicylic acid-independent ENHANCED DISEASE SUSCEPTIBILITY1 signaling in Arabidopsis immunity and cell death is regulated by the monooxygenase FMO1 and the Nudix hydrolase NUDT7. Plant Cell 18, 1038-1051 (2006).

14. Koch, M. et al. A role for a flavin-containing mono-oxygenase in resistance against microbial pathogens in Arabidopsis. Plant J. 47, 629-639 (2006).

15. Mishina, T. E. \& Zeier, J. The Arabidopsis flavin-dependent monooxygenase FMO1 is an essential component of biologically induced systemic acquired resistance. Plant Physiol. 141, 1666-1675 (2006).

16. Song, J. T., Lu, H. \& Greenberg, J. T. Divergent roles in Arabidopsis thaliana development and defense of two homologous genes, aberrant growth and death 2 and agd2-like defense response protein 1, encoding novel aminotransferases. Plant Cell 16, 353-366 (2004).

17. Jagadeeswaran, G. et al. Arabidopsis GH3-LIKE DEFENSE GENE 1 is required for accumulation of salicylic acid, activation of defense responses and resistance to Pseudomonas syringae. Plant J. 51, 234-246 (2007).

18. Lee, M. W., Lu, H., Jung, H. W. \& Greenberg, J. T. A key role for the Arabidopsis WIN3 protein in disease resistance triggered by Pseudomonas syringae that secrete AvrRpt2. Mol. Plant Microbe Interact. 20, 1192-1200 (2007).

19. Nobuta, K. et al. The GH3 acyl adenylase family member PBS3 regulates salicylic acid-dependent defense responses in Arabidopsis. Plant Physiol. 144, 1144-1156 (2007).

20. Song, J. T., Lu, H., McDowell, J. M. \& Greenberg, J. T. A key role for ALD1 in activation of local and systemic defenses in Arabidopsis. Plant J. 40, 200-212 (2004).

21. Jing, B. et al. Brush and spray: a high-throughput systemic acquired resistance assay suitable for large-scale genetic screening. Plant Physiol. 157, 973-980 (2011).

22. Navarova, H., Bernsdorff, F., Doring, A. C. \& Zeier, J. Pipecolic acid, an endogenous mediator of defense amplification and priming, is a critical regulator of inducible plant immunity. Plant Cell 24, 5123-5141 (2012).

23. Wang, L. et al. Arabidopsis CaM binding protein CBP60g contributes to MAMP-induced SA accumulation and is involved in disease resistance against Pseudomonas syringae. PLoS Pathog. 5, e1000301 (2009).

24. Zhang, Y. et al. Control of salicylic acid synthesis and systemic acquired resistance by two members of a plant-specific family of transcription factors. Proc. Natl Acad. Sci. USA 107, 18220-18225 (2010).

25. Wang, L. et al. CBP60g and SARD1 play partially redundant critical roles in salicylic acid signaling. Plant J. 67, 1029-1041 (2011).

26. Zhang, Y. et al. Arabidopsis snc2-1D activates receptor-like protein-mediated immunity transduced through WRKY70. Plant Cell 22, 3153-3163 (2010).

27. Yang, Y. et al. The ankyrin-repeat transmembrane protein BDA1 functions downstream of the receptor-like protein SNC2 to regulate plant immunity. Plant Physiol. 159, 1857-1865 (2012).

28. Truman, W. \& Glazebrook, J. Co-expression analysis identifies putative targets for CBP60g and SARD1 regulation. BMC Plant Biol. 12, 216 (2012).

29. Aarts, N. et al. Different requirements for $E D S 1$ and NDR1 by disease resistance genes define at least two $R$ gene-mediated signaling pathways in Arabidopsis. Proc. Natl Acad. Sci. USA 95, 10306-10311 (1998).

30. Parker, J. E. et al. Characterization of eds1, a mutation in Arabidopsis suppressing resistance to Peronospora parasitica specified by several different RPP genes. Plant Cell 8, 2033-2046 (1996).

31. Glazebrook, J., Rogers, E. E. \& Ausubel, F. M. Isolation of Arabidopsis mutants with enhanced disease susceptibility by direct screening. Genetics 143, 973-982 (1996).

32. Jirage, D. et al. Arabidopsis thaliana PAD4 encodes a lipase-like gene that is important for salicylic acid signaling. Proc. Natl Acad. Sci. USA 96, 13583-13588 (1999). 
33. Falk, A. et al. EDS1, an essential component of $R$ gene-mediated disease resistance in Arabidopsis has homology to eukaryotic lipases. Proc. Natl Acad. Sci. USA 96, 3292-3297 (1999).

34. Century, K. S. et al. NDR1, a pathogen-induced component required for Arabidopsis disease resistance. Science 278, 1963-1965 (1997).

35. Bonardi, V. et al. Expanded functions for a family of plant intracellular immune receptors beyond specific recognition of pathogen effectors. Proc. Natl Acad. Sci. USA 108, 16463-16468 (2011).

36. Roux, M. et al. The Arabidopsis leucine-rich repeat receptor-like kinases BAK1/ SERK3 and BKK1/SERK4 are required for innate immunity to hemibiotrophic and biotrophic pathogens. Plant Cell 23, 2440-2455 (2011).

37. Chinchilla, D. et al. A flagellin-induced complex of the receptor FLS2 and BAK1 initiates plant defence. Nature 448, 497-500 (2007).

38. Heese, A. et al. The receptor-like kinase SERK3/BAK1 is a central regulator of innate immunity in plants. Proc. Natl Acad. Sci. USA 104, 12217-12222 (2007).

39. Liu, J. et al. Heterotrimeric G proteins serve as a converging point in plant defense signaling activated by multiple receptor-like kinases. Plant Physiol. 161, 2146-2158 (2013).

40. Torres, M. A., Morales, J., Sanchez-Rodriguez, C., Molina, A. \& Dangl, J. L. Functional interplay between Arabidopsis NADPH oxidases and heterotrimeric G protein. Mol. Plant Microbe Interact. 26, 686-694 (2013).

41. Ishikawa, A. The Arabidopsis G-protein beta-subunit is required for defense response against Agrobacterium tumefaciens. Biosci. Biotechnol. Biochem. 73, 47-52 (2009).

42. Kadota, Y. et al. Direct Regulation of the NADPH Oxidase RBOHD by the PRR-Associated Kinase BIK1 during Plant Immunity. Mol. Cell 54, 43-55 (2014).

43. Li, L. et al. The FLS2-associated kinase BIK1 directly phosphorylates the NADPH oxidase RbohD to control plant immunity. Cell. Host. Microbe. 15, 329-338 (2014)

44. Lu, D. et al. A receptor-like cytoplasmic kinase, BIK1, associates with a flagellin receptor complex to initiate plant innate immunity. Proc. Natl. Acad. Sci. USA 107, 496-501 (2010).

45. Zhang, J. et al. Receptor-like cytoplasmic kinases integrate signaling from multiple plant immune receptors and are targeted by a Pseudomonas syringae effector. Cell. Host. Microbe. 7, 290-301 (2010).

46. Zhang, Z. et al. Disruption of PAMP-induced MAP kinase cascade by a Pseudomonas syringae effector activates plant immunity mediated by the NB-LRR protein SUMM2. Cell. Host. Microbe. 11, 253-263 (2012).

47. Asai, T. et al. MAP kinase signalling cascade in Arabidopsis innate immunity. Nature 415, 977-983 (2002)

48. Boudsocq, M. et al. Differential innate immune signalling via $\mathrm{Ca}(2+)$ sensor protein kinases. Nature 464, 418-422 (2010).

49. Gomez-Gomez, L. \& Boller, T. FLS2: an LRR receptor-like kinase involved in the perception of the bacterial elicitor flagellin in Arabidopsis. Mol. Cell 5, 1003-1011 (2000).

50. Feys, B. J., Moisan, L. J., Newman, M. A. \& Parker, J. E. Direct interaction between the Arabidopsis disease resistance signaling proteins, EDS1 and PAD4. Embo J. 20, 5400-5411 (2001).

51. Gao, M. et al. MEKK1, MKK1/MKK2 and MPK4 function together in a mitogen-activated protein kinase cascade to regulate innate immunity in plants. Cell Res. 18, 1190-1198 (2008).

52. Ichimura, K., Casais, C., Peck, S. C., Shinozaki, K. \& Shirasu, K. MEKK1 is required for MPK4 activation and regulates tissue-specific and temperaturedependent cell death in Arabidopsis. J. Biol. Chem. 281, 36969-36976 (2006).

53. Nakagami, H., Soukupova, H., Schikora, A., Zarsky, V. \& Hirt, H. A Mitogenactivated protein kinase kinase kinase mediates reactive oxygen species homeostasis in Arabidopsis. J. Biol. Chem. 281, 38697-38704 (2006).

54. Suarez-Rodriguez, M. C. et al. MEKK1 is required for flg22-induced MPK4 activation in Arabidopsis plants. Plant Physiol. 143, 661-669 (2007).

55. Li, W. et al. The U-Box/ARM E3 ligase PUB13 regulates cell death, defense, and flowering time in Arabidopsis. Plant Physiol. 159, 239-250 (2012).

56. Lu, D. et al. Direct ubiquitination of pattern recognition receptor FLS2 attenuates plant innate immunity. Science 332, 1439-1442 (2011).

57. Xu, X., Chen, C., Fan, B. \& Chen, Z. Physical and functional interactions between pathogen-induced Arabidopsis WRKY18, WRKY40, and WRKY60 transcription factors. Plant Cell 18, 1310-1326 (2006).

58. Shen, Q. H. et al. Nuclear activity of MLA immune receptors links isolatespecific and basal disease-resistance responses. Science 315, 1098-1103 (2007).
59. Ge, X. et al. AtNUDT7, a negative regulator of basal immunity in Arabidopsis, modulates two distinct defense response pathways and is involved in maintaining redox homeostasis. Plant Physiol. 145, 204-215 (2007).

60. Wang, H. et al. The ammonium/nitrate ratio is an input signal in the temperature-modulated, SNC1-mediated and EDS1-dependent autoimmunity of nudt6-2 nudt7. Plant J. 73, 262-275 (2013).

61. Consonni, C. et al. Conserved requirement for a plant host cell protein in powdery mildew pathogenesis. Nat. Genet. 38, 716-720 (2006).

62. Yang, S. \& Hua, J. A haplotype-specific Resistance gene regulated by BONZAI1 mediates temperature-dependent growth control in Arabidopsis. Plant Cell 16, 1060-1071 (2004).

63. Yang, H., Li, Y. \& Hua, J. The C2 domain protein BAP1 negatively regulates defense responses in Arabidopsis. Plant J. 48 (2006).

64. Yang, H., Yang, S., Li, Y. \& Hua, J. The Arabidopsis BAP1 and BAP2 genes are general inhibitors of programmed cell death. Plant Physiol. 145, 135-146 (2007).

65. Li, X., Zhang, Y., Clarke, J. D., Li, Y. \& Dong, X. Identification and cloning of a negative regulator of systemic acquired resistance, SNI1, through a screen for suppressors of npr1-1. Cell 98, 329-339 (1999).

66. Bi, D., Cheng, Y. T., Li, X. \& Zhang, Y. Activation of plant immune responses by a gain-of-function mutation in an atypical receptor-like kinase. Plant Physiol. 153, 1771-1779 (2010).

67. Cheng, Y. T. et al. Nuclear pore complex component MOS7/Nup88 is required for innate immunity and nuclear accumulation of defense regulators in Arabidopsis. Plant Cell 21, 2503-2516 (2009).

68. Langmead, B., Trapnell, C., Pop, M. \& Salzberg, S. L. Ultrafast and memoryefficient alignment of short DNA sequences to the human genome. Genome Biol. 10, R25 (2009).

69. Li, H. et al. The Sequence Alignment/Map format and SAMtools. Bioinformatics 25, 2078-2079 (2009).

70. Bailey, T. L. DREME: motif discovery in transcription factor ChIP-seq data. Bioinformatics 27, 1653-1659 (2011).

\section{Acknowledgements}

We thank Dr Xin Li and Mr Paul Kapos from the University of British Columbia for careful reading and discussion of the manuscript. We are grateful for the financial support to Y.L.Z. from Natural Sciences and Engineering Research Council of Canada and Canada Foundation for Innovation.

\section{Author contributions}

Conceived and designed the experiments: T.S., Y.X.Z. and Y.L.Z. Performed the experiments: T.S., Y.X.Z., Q.Z. and Y.D. Analysed the data: T.S., Y.L. and Y.L.Z. Wrote the paper: T.S. and Y.L.Z.

\section{Additional information}

Accession codes: The ChIP-seq data is deposited in the NCBI Sequence Read Archive with accession number: SRX1371906.

Supplementary Information accompanies this paper at http://www.nature.com/ naturecommunications

Competing financial interests: The authors declare no competing financial interests.

Reprints and permission information is available online at http://npg.nature.com/ reprintsandpermissions/

How to cite this article: Sun, T. et al. ChIP-seq reveals broad roles of SARD1 and CBP60g in regulating plant immunity. Nat. Commun. 6:10159 doi: 10.1038/ncomms10159 (2015).

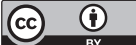

This work is licensed under a Creative Commons Attribution 4.0 International License. The images or other third party material in this article are included in the article's Creative Commons license, unless indicated otherwise in the credit line; if the material is not included under the Creative Commons license, users will need to obtain permission from the license holder to reproduce the material. To view a copy of this license, visit http://creativecommons.org/licenses/by/4.0/ 